\title{
Cancer cell-binding peptide fused Fc domain activates immune effector cells and blocks tumor growth
}

\author{
Anne Mobergslien ${ }^{1}$, Qian Peng ${ }^{2}$, Vlada Vasovic ${ }^{2}$, Mouldy Sioud ${ }^{1}$ \\ ${ }^{1}$ Department of Cancer Immunology, Institute for Cancer Research, Oslo University Hospital-Radiumhospitalet, N-0310 \\ Oslo, Norway \\ ${ }^{2}$ Department of Pathology, Institute for Cancer Research, Oslo University Hospital-Radiumhospitalet, N-0310 Oslo, Norway \\ Correspondence to: Mouldy Sioud, email: Mouldy.Sioud@rr-research.no \\ Keywords: Fc-fusion proteins, innate effector cells, NK cells, immunotherapy, immunostimulation \\ Received: February 17, $2016 \quad$ Accepted: September 24, $2016 \quad$ Published: October 04, 2016
}

\section{ABSTRACT}

Therapeutic strategies aiming at mobilizing immune effector cells to kill tumor cells independent of tumor mutational load and MHC expression status are expected to benefit cancer patients. Recently, we engineered various peptide-Fc fusion proteins for directing $\mathrm{Fc} \eta$ receptor-bearing immune cells toward tumor cells. Here, we investigated the immunostimulatory and anti-tumor effects of one of the engineered Fc fusion proteins (WN-Fc). In contrast to the Fc control, soluble WN-Fc-1 fusion protein activated innate immune cells (e.g. monocytes, macrophages, dendritic cells, NK cells), resulting in cytokine production and surface display of the lytic granule marker CD107a on NK cells. An engineered Fc-fusion variant carrying two peptide sequences (WN-Fc-2) also activated immune cells and bound to various cancer cell types with high affinity, including the murine 4T1 breast carcinoma cells. When injected into 4T1 tumor-bearing BALB/C mice, both peptide-Fc fusions accumulated in tumor tissues as compared to other organs such as the lungs. Moreover, treatment of 4T1 tumor-bearing BALB/C mice by means of two intravenous injections of the WN-Fc fusion proteins inhibited tumor growth with WN-Fc-2 being more effective than WN-Fc-1. Treatment resulted in tumor infiltration by $\mathrm{T}$ cells and $\mathrm{NK}$ cells. These new engineered $\mathrm{WN}$-Fc fusion proteins may be a promising alternative to existing immunotherapies for cancer.

\section{INTRODUCTION}

In spite of significant progress in recent years towards the development of new targeted therapies, cancer is still a largely unmet medical need [1]. Among the new therapeutics, checkpoints blocking antibodies, such as anti-CTLA-4 and anti-PD1, represent a therapeutic strategy that has shown great promise in cancer [2]. However, checkpoint inhibitors work best in tumors with high mutational load (neoantigens) such as melanoma, but are less successful in many solid tumors and B cell malignancies $[3,4,5]$. Moreover, most tumors escape traditional T-cell killing via alteration of their antigen processing machinery and/or down-regulation of MHC class I expression, rendering the neoantigens undetectable by the immune system [6]. In contrast to checkpoint inhibitors, the clinical efficacy of several monoclonal antibodies (mAbs) such as retixumab, herceptin, and cetixumab, is largely dependent on the patient's innate immune effector cells [7]. Indeed, the engagement of the antibody Fc domain with the Fc $\gamma$ receptors expressed by innate immune cells such as natural killer (NK) cells and macrophages triggers antibody-dependent cellular cytotoxicity (ADCC) and phagocytosis of tumor cells $[9,10]$. The contribution of ADCC to antibody efficacy in patients is also supported by studies demonstrating associations between therapeutic efficacy and the expression of certain $\mathrm{Fc} \gamma$ receptor allotypes [11]. Fc $\gamma \mathrm{R}$ activation can be stimulatory or inhibitory to effector cells, depending on which receptor is triggered and which cells are activated [12]. With respect to cancer immunotherapy, NK cells are central in that they express only the activating Fc $\gamma$ RIIIa receptor (CD16) and no inhibitory antibody receptors underscoring a major role in promoting tumor cell killing [13].

Although Ab therapy has led to important clinical advances, most of the used Abs have targeted surface antigens whose repertoire on solid tumors is limited [11]. Owing to their full-size, Abs are also impeded from entering solid tumors, calling for the development of new 
targeted therapies [14]. To increase the spectrum of tumor antigens that can be targeted by Abs in solid tumors, we have explored the use of cancer cell-binding peptides selected from peptide phage libraries as a targeting moiety [15]. By fusing such peptides to human IgG-1 Fc domain, we have married the targeting specificities of the peptides with the effector function of Abs such as the induction of ADCC. The engineered peptide-Fc fusion proteins, particularly the WN-Fc variant, bound to various cancer cell types. Given the involvement of innate immune cells in antibody clinical efficacy and the binding of the engineered peptide Fc fusions to cancer cells, here we have investigated whether soluble WN-Fc fusion proteins could function as an adjuvant and inhibit tumor growth in mice.

\section{RESULTS}

\section{Engineering WN peptide-Fc fusion proteins}

We first wanted to improve the binding affinity of the WN-Fc fusion protein to cancer cells by fusing two copies of the targeting WN peptide (WNLPWYYSVSPT) to a single human IgG1 Fc domain as illustrated in Figure 1A. Recombinant peptide-Fc fusion proteins were expressed in HEK293 cells and then purified on protein G chromatography. The purity of the engineered proteins was higher than $98 \%$ as revealed by SDS-PAGE and Western blots (Figure $1 \mathrm{~B}$ and $1 \mathrm{C}$ ). As a result of glycosylation, the apparent molecular mass of recombinant human $\mathrm{Fc}$ is around $32 \mathrm{kDa}$ in SDS-PAGE under reducing conditions. Under our experimental conditions, both WN-Fc-1 and $\mathrm{WN}-\mathrm{Fc}-2$ ran as slightly diffuse bands; reflecting structure-related effect.

We next assessed the ability of the engineered proteins to bind human lung (SW900), breast (SKBR3), and glioma (T98G) cancer cell lines (Figure 1D). In contrast to the Fc control (blue histograms), WN-Fc-1 displayed a strong binding to all three tested cell lines (orange histograms). The expression of two peptide sequences in a single Fc domain (WN-Fc-2) increased the binding (green histograms). As shown in Figure 1D, WN-Fc-1 and WN-Fc-2 fusion proteins bound to $4 \mathrm{~T} 1$
A

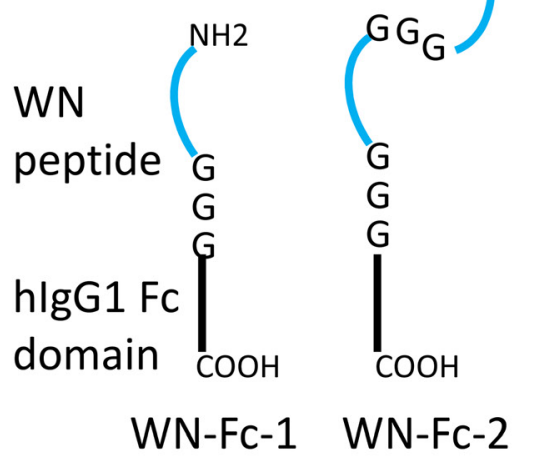

D
$B$

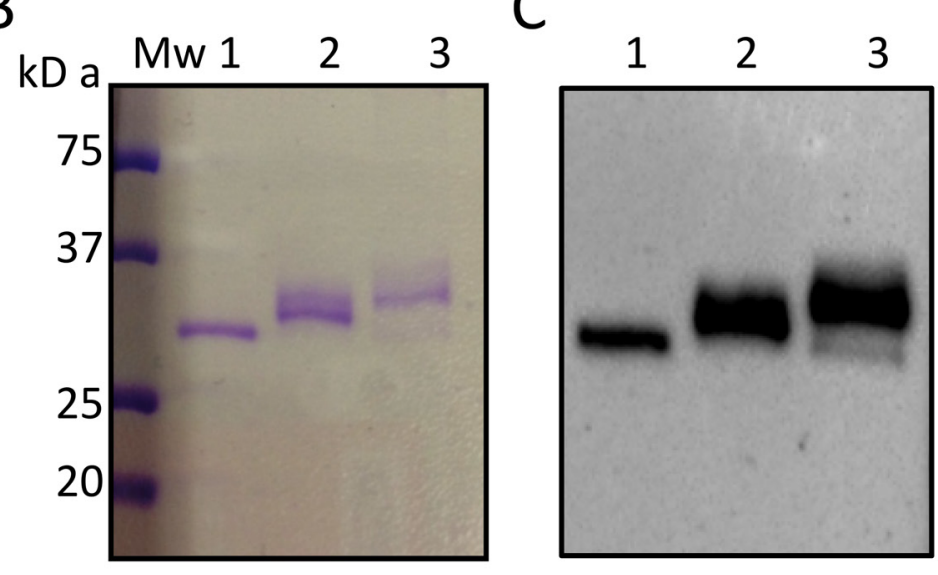

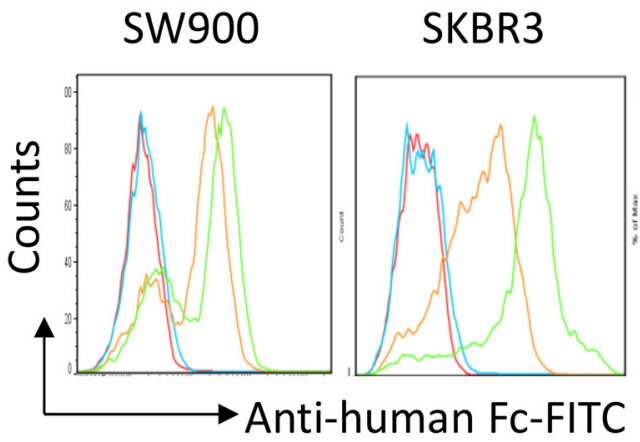

T98G

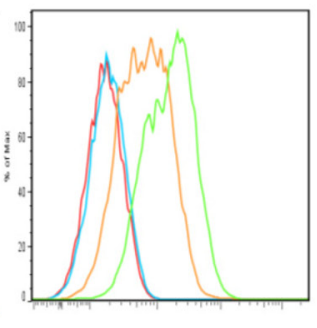

$4 \mathrm{~T} 1$

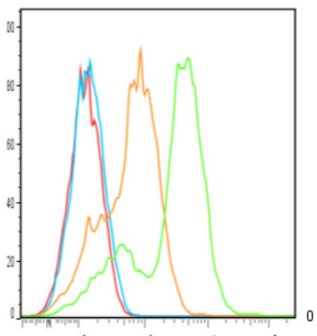

CD4+ T cells

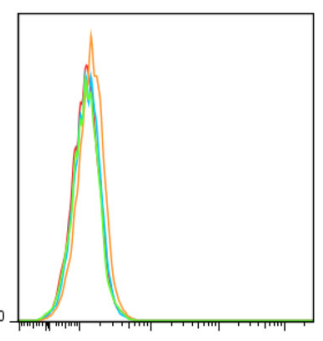

Figure 1: Characterization of the peptide-Fc fusion proteins. A. Schematic representation of WN-Fc-1 and WN-Fc-2 constructs. B. Analysis of purified Fc fusion proteins by SDS-PAGE followed by Coomassie staining. C. Western blot analysis with an anti-human Fc monoclonal antibody. Lanes 1 to 3 correspond to Fc control, WN-Fc-1, and WN-Fc-2 fusion proteins, respectively. D. Binding of Fc control, WN-Fc-1, and WN-Fc-2 to cancer cell lines and human CD4+ T cells. The cells were stained with the recombinant proteins $(5 \mu \mathrm{g} /$ $\mathrm{ml}$ ) and then analyzed by flow cytometry. Blue, orange and green histograms represent cells stained with Fc control, WN-Fc-1, or WN-Fc-2, respectively. Red histograms = cells stained with only FITC-conjugated anti-human Fc antibody. The data are from one single experiment and are representative of five independent experiments. 
murine mammary carcinoma cell line, while no significant binding was seen with human peripheral blood CD4+ T lymphocytes. Under our experimental conditions, The WN-Fc-2 bound to SW900, SKBR3, T98G, and 4T1 cells with apparent affinities of $15 \pm 3 \mathrm{nM}, 7 \pm 2 \mathrm{nM}, 20 \pm 5$ $\mathrm{nM}$, and $8 \pm 2 \mathrm{nM}$, respectively.

\section{Soluble WN-peptide-Fc fusion proteins activate immune cells}

Engineering anti-tumor Fc-fusion proteins for optimal activity requires a clear understanding of their interactions with immune effector cells. Therefore, we assessed the effects of the engineered proteins on cytokine production by freshly isolated peripheral blood mononuclear cells (PBMCs). Following $16 \mathrm{~h}$ stimulation of PBMCs with WN-Fc-1, WN-Fc-2 or Fc control, culture supernatants were harvested and cytokine contents were measure by ELISA (Figure 2A). Cells stimulated with WN-Fc-1 or WN-Fc-2 secreted significant levels of TNF- $\alpha$, IL- 6 and INF- $\gamma$, whereas those stimulated with Fc control did not secrete cytokines when compared to unstimulated cells. Similarly, treatment of blood monocytes, M1 macrophages and immature DCs with WN-Fc-1 and WN-Fc-2 induced TNF- $\alpha$ expression (Figure 2B). Again, stimulation with the Fc control had no effect on cytokine production. M2 macrophages also responded to WN-Fc fusion proteins (data not shown). Immature DCs exposed to WN-Fc-2 fusion protein upregulated the expression of costimulatory molecules such as CD86 (Figure 2C). A significant increase in mean fluorescence intensity is evident when compared to the Fc control-treated cells (4604 versus 2451, $P<0.001$ ). Collectively, these results indicate that the WN-Fc fusion
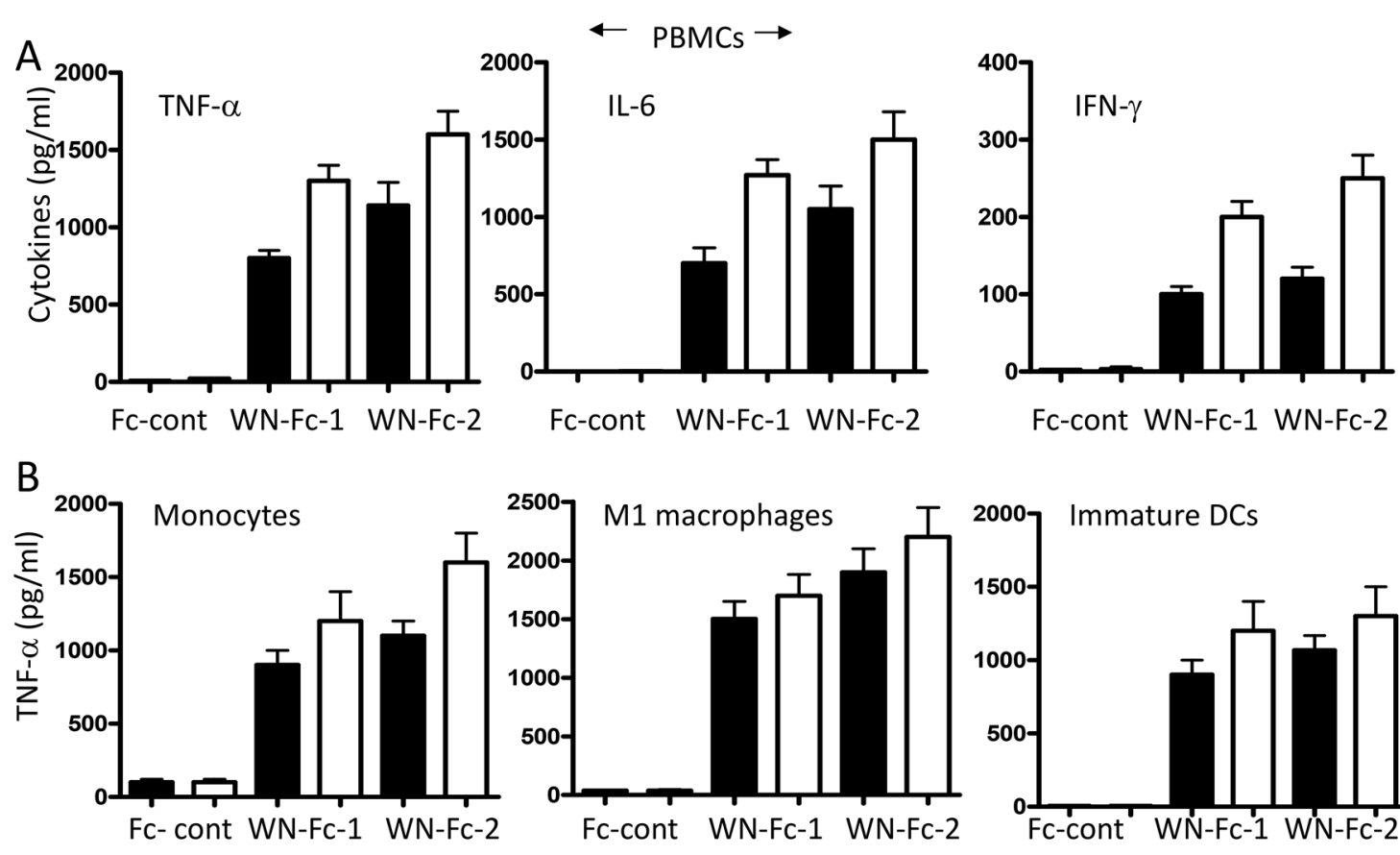

Fc-cont WN-Fc-1 WN-Fc-2
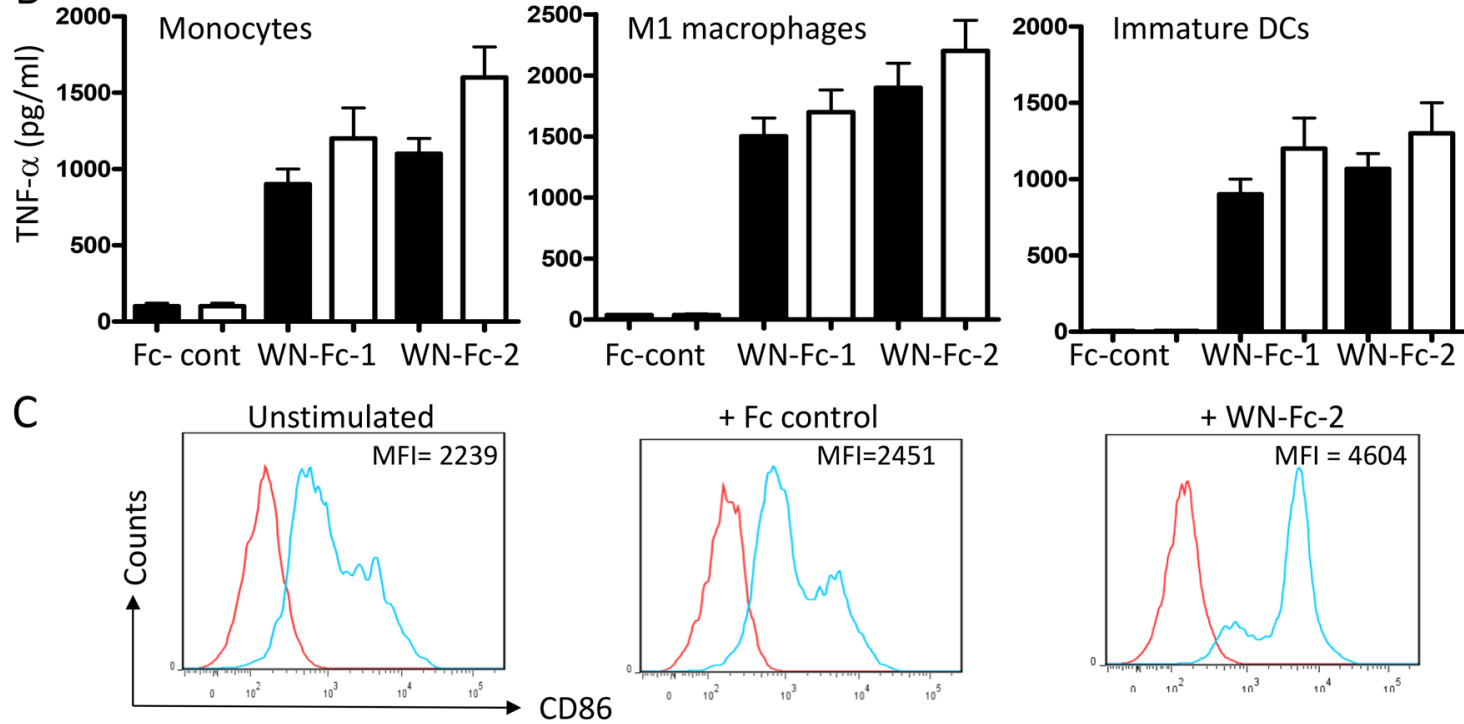

Figure 2: Activation of blood cells in response to soluble WN-Fc-1 and WN-Fc-2. A. PBMCs were incubated for $16 \mathrm{~h}$ in $\mathrm{X}$-VIVO 15 medium alone or medium supplemented with WN-Fc-1, WN-Fc-2, or Fc control (5 or $10 \mu \mathrm{g} / \mathrm{ml}$, black and white columns, respectively). Culture supernatants were harvested and analyzed for TNF- $\alpha$ and IFN- $\gamma$ contents by ELISA. B. Similarly, monocytes, M1 macrophages, and immature DC were stimulated with the test molecules as described in A and TNF- $\alpha$ contents in culture supernatants were determined by ELISA. The results in A and $\mathrm{B}$ are represented as means $\pm \mathrm{SD}$ from triplicate determinations and are representative of at least five independent experiments using NK cells from different donors. C. Expression of CD86 co-stimulatory molecule. Immature DCs were stimulated with Fc control or WN-Fc-2 (10 $\mu \mathrm{g} / \mathrm{ml}$ each) for $48 \mathrm{~h}$ and then the CD86 expression was analyzed by flow cytometry. The results are representative of four independent experiments. 
proteins could be used as adjuvant to activate immune effector cells such as macrophages and DCs, an important antigen presenting cells for promoting immunity against tumor cells.

\section{WN-Fc fusion proteins efficiently activate NK cells}

Given the central role played by NK cells in cancer immunotherapy [9], we next evaluated the relative ability of soluble $\mathrm{WN}-\mathrm{Fc}-1$ and $\mathrm{WN}-\mathrm{Fc}-2$ to stimulate NK cell Fc $\gamma$ RIIIa receptor. Freshly isolated blood NK cells were stimulated for $16 \mathrm{~h}$ with WNFc-1 or WN-Fc-2 in the presence or absence of IL-15 $(10 \mathrm{ng} / \mathrm{ml})$. As illustrated in Figure 3A, WN-Fc-1 and WN-Fc-2 activated resting NK cells as revealed by the up-regulation of CD69 activation marker (orange and green histograms, respectively). Under the same experimental conditions, soluble Fc control did not induce CD69 expression (blue histogram). Additional exposure of NK cells to IL-15 generally increased their reactivity without altering the differential effects of
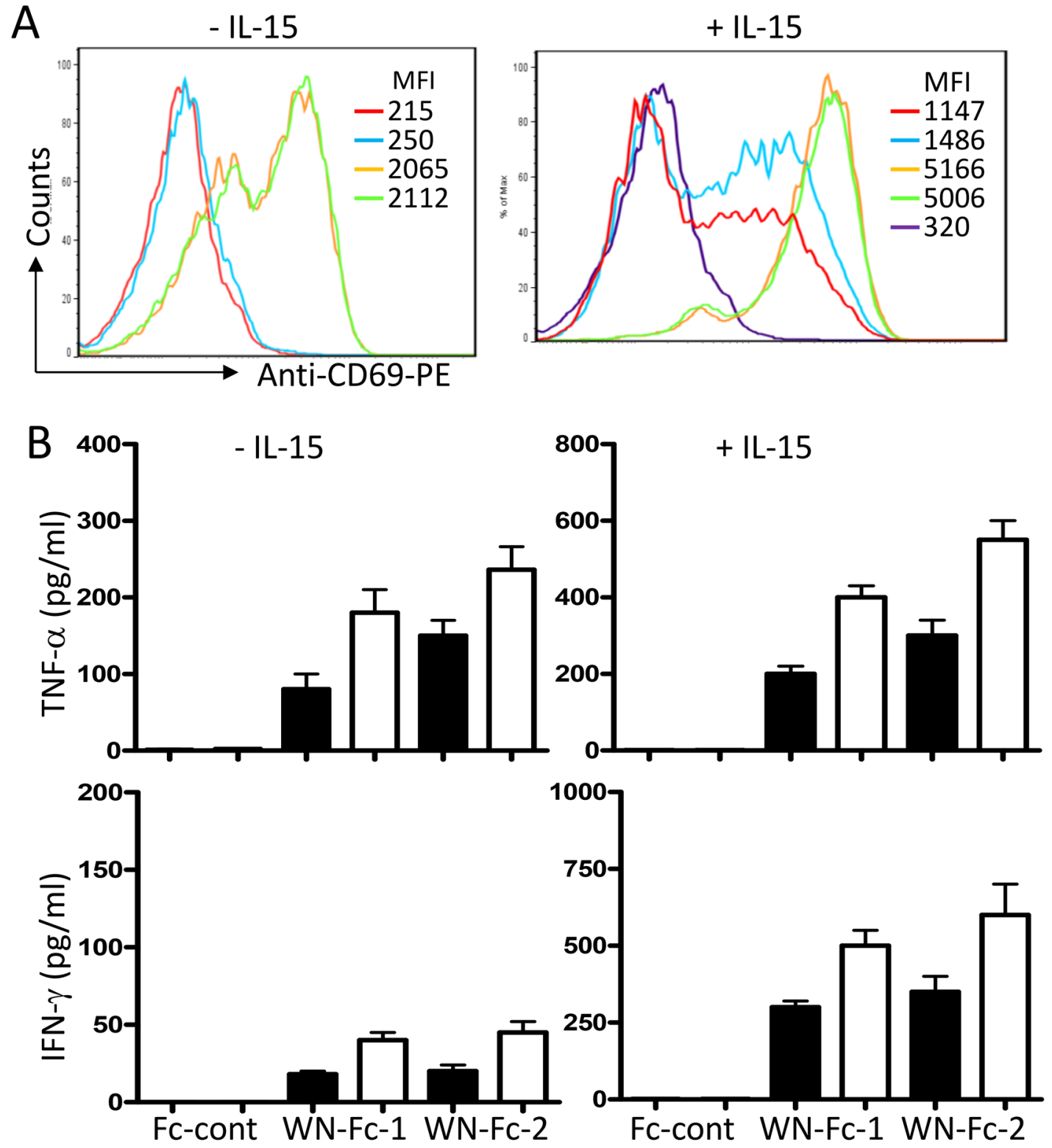

Figure 3: Activation of NK cells in response to WN-Fc-1 and WN-Fc-2. A. NK cells were stimulated with WN-Fc-1, WN-Fc-2, or Fc control (10 $\mu \mathrm{g} / \mathrm{ml}$ each) for $16 \mathrm{~h}$ in X-VIVO 15 supplemented (+) or not (-) with IL-15. Thereafter, the cells were stained for CD69 expression and analyzed by flow cytometry. The data are representative of at least five independent experiments. MFI $=$ mean fluorescence intensity. B. As in A, NK cells were stimulated with the test molecules ( 5 or $10 \mu \mathrm{g} / \mathrm{ml}$, black and white columns, respectively) for $16 \mathrm{~h}$ and then secreted TNF- $\alpha$ and IFN- $\gamma$ were measured by ELISA. The results are represented as means \pm SD from triplicate determinations and are representative of five independent experiments using NK cells from different donors. 
WN-Fc-1 and WN-Fc-2 over the Fc control (Figure 3A, a representative example). We also measured TNF- $\alpha$ and INF- $\gamma$ production in response to soluble $\mathrm{WN}$ Fc-1 and WN-Fc-2 (Figure 3B). NK cells stimulated for $16 \mathrm{~h}$ with WN-Fc-1 or WN-Fc-2 secreted TNF- $\alpha$ and IFN- $\gamma$, whereas those stimulated with Fc control did not. Similarly, cytokine production was enhanced when NK cells were co-stimulated with IL-15, which is an important regulator of $\mathrm{NK}$ cell development, homeostasis and activation [17].

\section{WN-Fc fusion proteins induce NK cell degranulation}

Recently, CD107a (also known as lysosomalassociated membrane protein-1, LAMP-1) expression on the cell surface has been described as a marker of NK cells and cytotoxic T cell degranulation [19, 20]. Such surface display also correlated with perforin secretion and destruction of tumor cells. Therefore, we measured the surface levels of CD107a in response to soluble WN-Fc-1 and WN-Fc-2 (Figure 4A). The percentage of CD107a positive cells was increased after $5 \mathrm{~h}$ stimulation. In the case of WN-Fc-2, CD107a expression on the surface of resting NK cells increased 21 -fold, resulting in $23 \%$ of CD56 positive cells expressing CD107a. Pre-activation of NK cells with IL-15 enhanced WN-Fc-1 and WN-Fc-2 specific effects on NK cell degranulation (37\% versus $23 \%$ and $34 \%$ versus $16.8 \%$, respectively, $P<0.01, \mathrm{n}=5)$. Similarly, WN-Fc-2-coated SKBR3 cells activated NK cells, leading to surface display of CD107a (Figure 4B). In these experiments, tumor cells were incubated with WNFc-2 for $30 \mathrm{~min}$ and then unbound WN-Fc molecules were removed by washing prior to co-stimulation with NK cells.

\section{Induction of ADCC by WN-Fc-2 fusion protein}

The potency of WN-Fc-2 to induce ADCC was subsequently evaluated using SKBR3 as target (T) cells and freshly isolated NK cells as effector (E) cells based on $\mathrm{LDH}$ release upon cell lysis [21]. As shown in Figure 5 , Both WN-Fc-1 and WN-Fc-2 induced a significant ADCC activity against SKBR3 $(40 \% \pm 5 \%$ and $53 \% \pm$ $8 \%$, respectively, at $\mathrm{E} / \mathrm{T}$ ratio $25: 1$ ) in comparison with
A
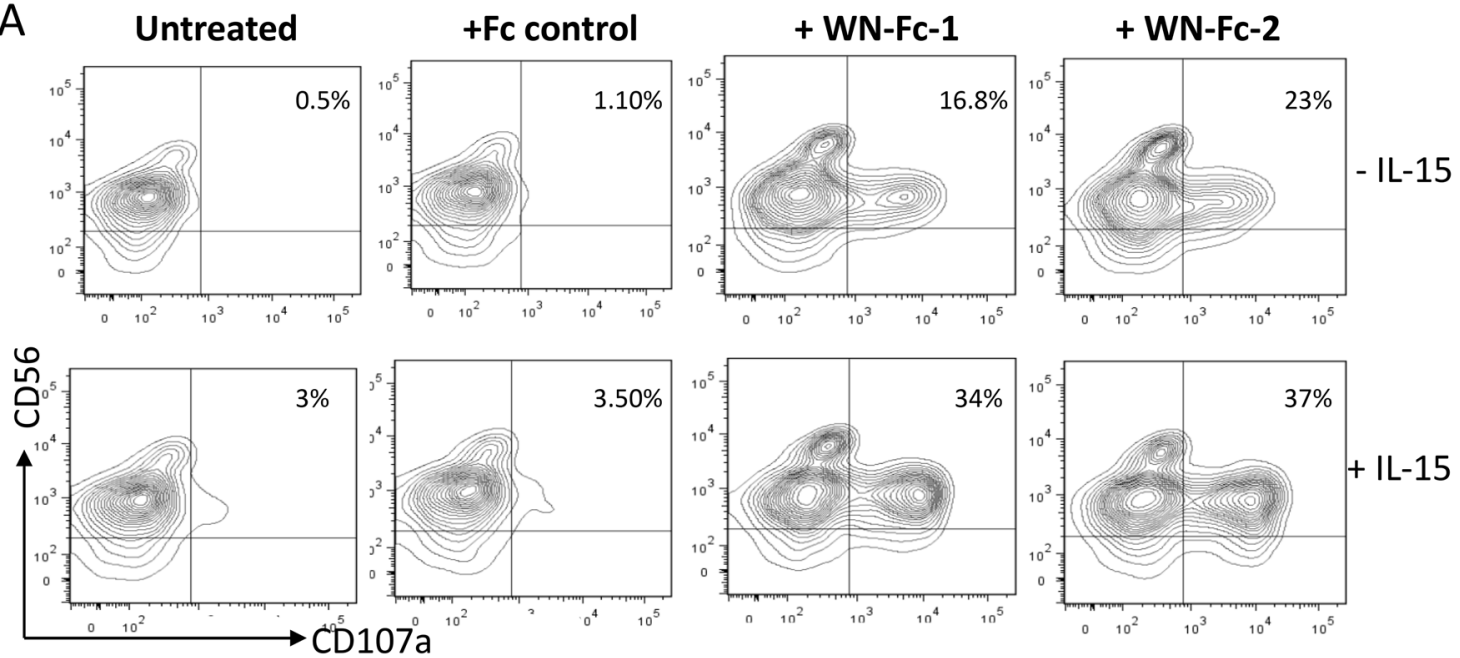

\section{B Untreated}

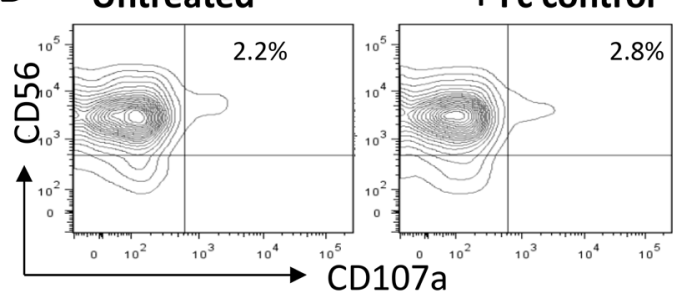

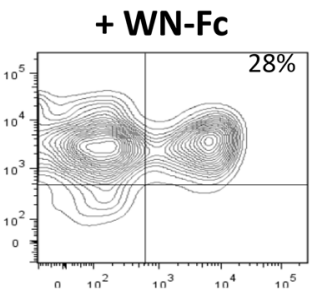

Figure 4: NK cell degranulation. A. Surface expression of CD107a by NK cells. Resting or IL-15-activated NK cells were stimulated with the indicated $\mathrm{Fc}$ fusion proteins $\left(10 \mu \mathrm{g} / \mathrm{ml}\right.$ each) and then analyzed for CD107a surface expression after $5 \mathrm{~h}$ incubation at $37^{\circ} \mathrm{C}$ in X-VIVO 15 medium. B. WN-Fc-coated SKBR3 activated NK cells. SKBR3 cells were incubated with WN-Fc-2 or Fc control for 30 min at room temperature. Thereafter, the cells were washed to remove unbound molecules and then incubated with $\mathrm{NK}$ cells for $5 \mathrm{~h}$ at $37^{\circ} \mathrm{C}$ and processed as in A. The data in A and B are from one single experiment and are representative of five independent experiments using NK cells from different donors. The numbers in dot plots represent the percentage of CD107a-positive NK cells. 
cells incubated with the Fc control $(13 \% \pm 3 \%$, at E/T ratio 25:1) $(P<0.02, \mathrm{n}=5)$. Thus, WN-Fc fusion proteins can function as immunostimulator and ADCC inducers. Again WN-Fc-2 showed more cytotoxic activity than WN-Fc-1.

\section{Targeting 4T1 cells in vitro and in vivo}

Binding of the WN peptide to its receptor has been shown to promote receptor internalization [22]. Therefore, we investigated whether WN-Fc fusion proteins are also internalized by 4T1 cells. Cells grown in tissue culture slides were incubated with rhodamine conjugated $\mathrm{WN}-\mathrm{Fc}$ fusion proteins at $4^{\circ} \mathrm{C}$. After washing, the cells were incubated at $37^{\circ} \mathrm{C}$ for $2 \mathrm{~h}$ to promote internalization. Both cell surface and intracellular staining were detected, indicating that cellbound WN-Fc fusion proteins were being internalized as well (Figure 6). Similarly, antibodies targeting epidermal growth factor receptor, such as Cetuximab which is approved for clinical use, also induce receptor internalization and ADCC [23].

To determine whether WN-Fc fusion proteins could target tumor cells in-vivo, rhodamine conjugated WN-Fc fusion proteins were injected i.v. into 4T1 tumor-bearing $\mathrm{BALB} / \mathrm{c}$ mice, before removing the tumors $18 \mathrm{~h}$ later to assess 4T1 tumor and normal organs for fluorescence (Figure 7, representative examples). As opposed to lung tissues, the data confirm the accumulation of WNFc fusion proteins in tumor tissues. Additionally, no significant fluorescence was detected in heart and kidney tissues (data not shown).

\section{Inhibition of tumor growth by the WN-Fc-2 fusion protein}

The Fc domain of human IgG1 seems to interact equally with murine and human effector cells such as NK cells [24]. Hence, mouse models are suitable for evaluating the Fc-mediated effect of human IgG1 $\mathrm{mAb}$ [25]. Given the binding of WN-Fc-2 to 4T1 murine mammary carcinoma cells (Figure 1D), we thus investigated its therapeutic potency using the 4T1 tumor model in syngeneic female BALB/c mice. The Fc control and WN-Fc-2 were administrated intravenously (100 $\mu \mathrm{g} /$ mouse/injection) at day 2 and 7 after subcutaneous tumor cell inoculation and tumor growth was monitored until day 20. Tumors were also harvested and weighted at day 20. As shown in Figure 8A, the average tumor volumes of mice receiving $\mathrm{WN}-\mathrm{Fc}-2$ were significantly smaller than those of the PBS- or Fc-control-treated mice $(P<0.005$ for WN-Fc-2 treatment versus PBStreatment and $P<0.01$ for WN-Fc- 2 treatment versus Fc control at day 20). When compared to both untreated and mice treated with the Fc control, the WN-Fc-2 significantly inhibited tumor growth at all time points. At day $20, \mathrm{WN}-\mathrm{Fc}-2$ treatment reduced the mean tumor weight from 1.8 to $1.06 \mathrm{~g}(P<0.003, \mathrm{n}=7$ mice per group). We have also compared the anti-tumor potency of WN-Fc-1 and WN-Fc-2 (Figure 8B). Treatment with WN-Fc-1 showed a significant anti-tumor effect when compared to untreated animals $(P<0.01, \mathrm{n}=7$ mice per group). Notably, WN-Fc-2 showed superior in vivo efficacy than WN-Fc-1 at the same concentration.

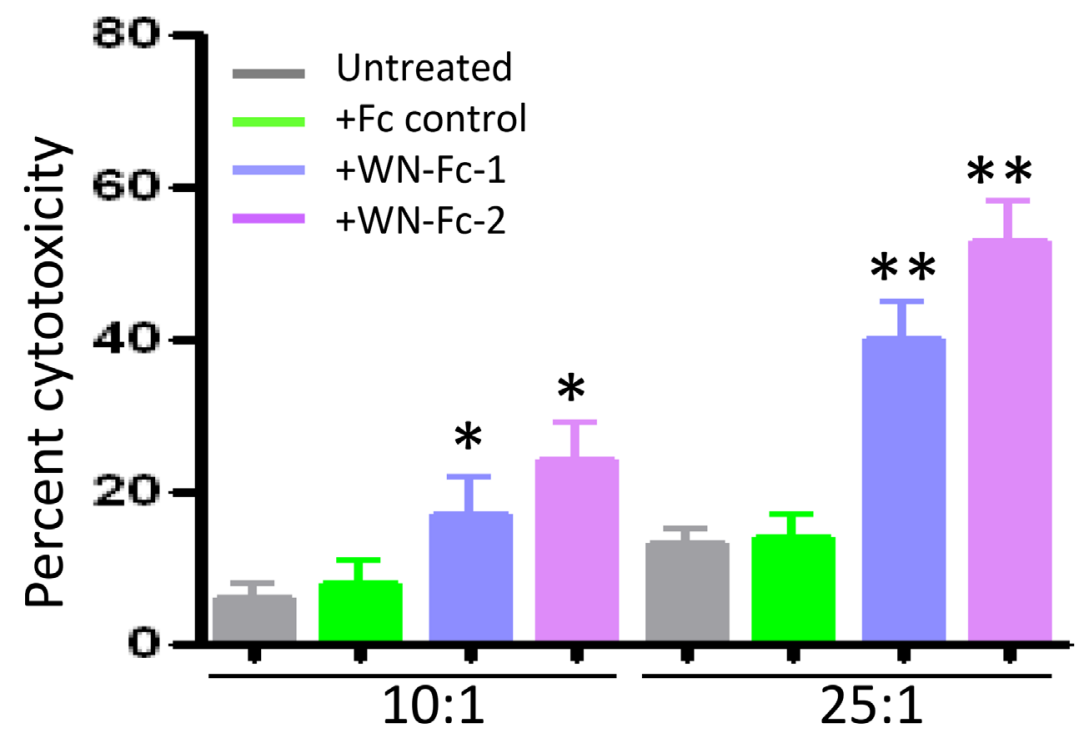

Figure 5: Induction of ADCC by WN-Fc fusion proteins. ADCC as measured by LDH release. SKBR3 target cells were preincubated with WN-Fc-1, WN-Fc-2, or Fc control for $30 \mathrm{~min}$ in X-VIVO medium. Thereafter, freshly isolated NK cells were added to the cells at ratio $12.5: 1$ or $25: 1$ effector to target cells. After $18 \mathrm{~h}$ incubation at $37^{\circ} \mathrm{C}$, culture supernatants were collected and analyzed for LDH. The results are represented as means \pm SD from triplicate determinations and are representative of four independent experiments using NK cells from different donors. Statistically significant differences between NW-Fc-2 treated cells and Fc control-treated cells are indicated by asterisks. ${ }^{*} P<0.05, * * P<0.02$. 
WN-Fc-1

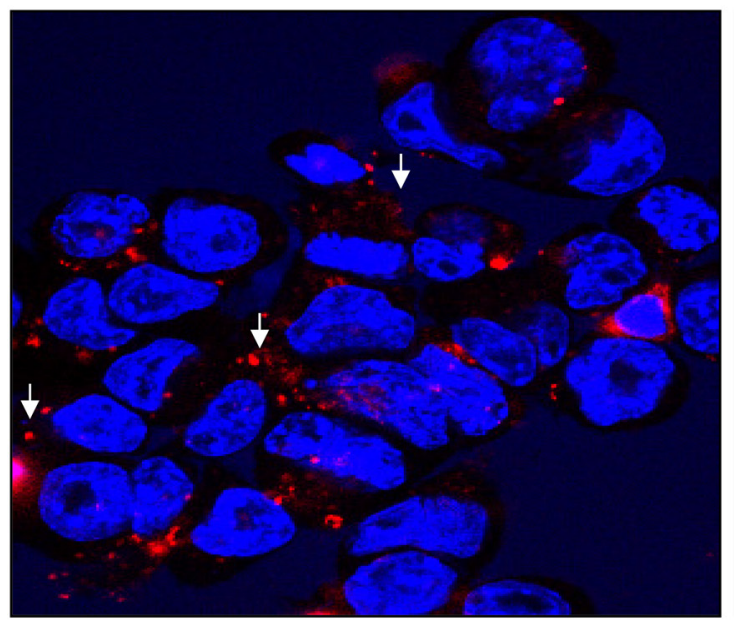

WN-Fc-2

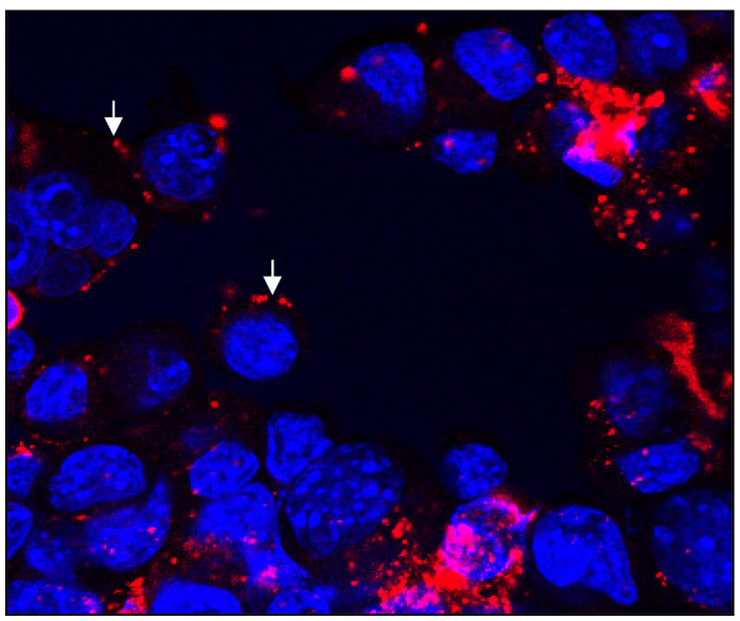

Figure 6: Binding and cellular uptake of WN-Fc fusion proteins. 4T1 cells growing in Lab-Tek chamber slides were incubated with rhodamine-conjugated WN-Fc fusion proteins, washed, fixed with paraformaldehyde, and then analyzed by confocal microscopy to check for surface binding and internalization. Nuclei were visualized with Hoeschst 33342 staining (blue). Representative images are shown (original magnification $\mathrm{x} 60$ ). The arrows indicate membrane staining.

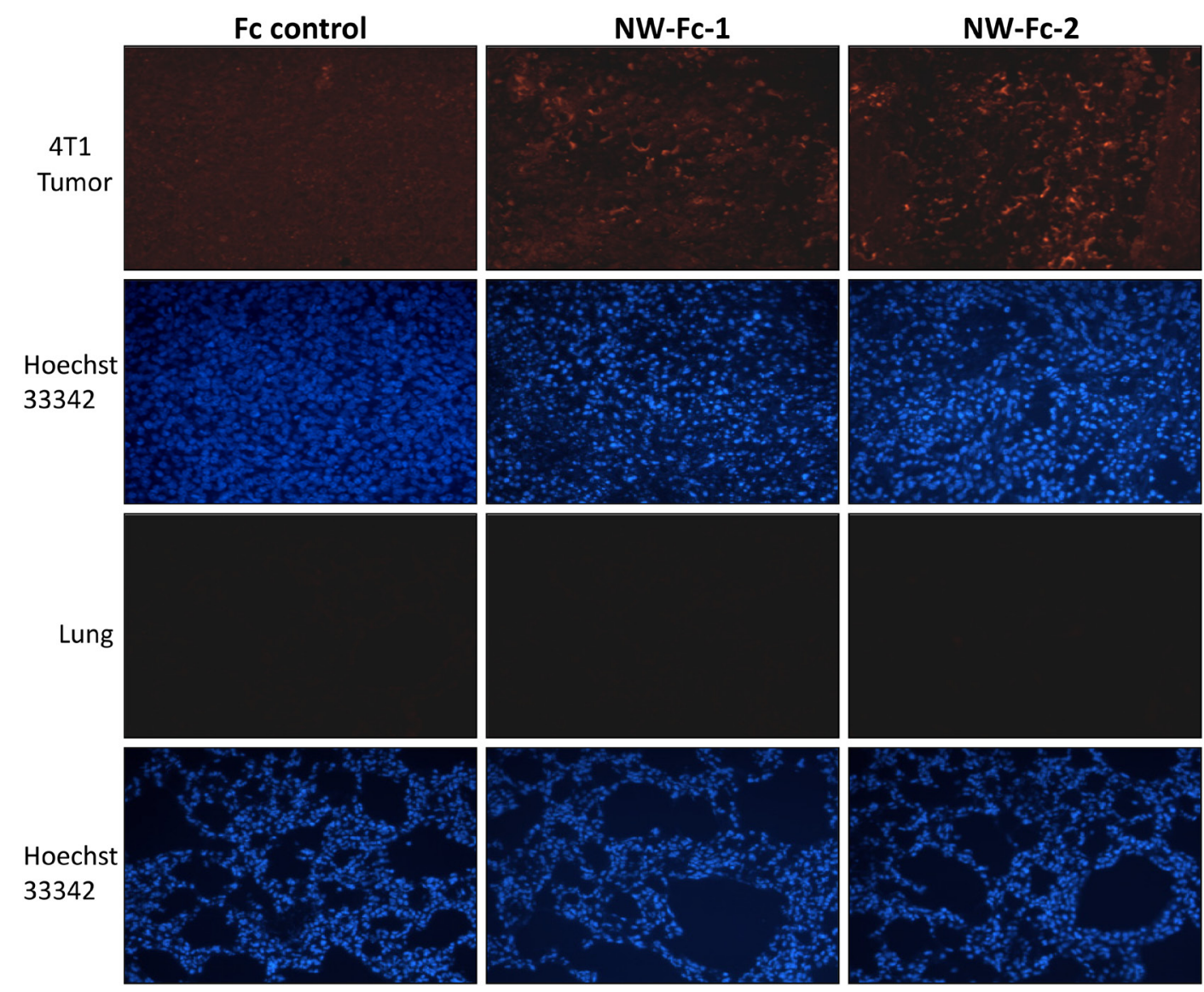

Figure 7: Fluorescence microscopy analysis of tumors and lung tissues. Rhodamine-conjugated NW-Fc fusion proteins or Fc control (200 $\mu \mathrm{g}$ each) was intravenously injected into the tail vein of mice bearing subcutaneous $4 \mathrm{~T} 1$ tumors. After $18 \mathrm{~h}$, tumors and others organs were removed, fixed with paraformaldehyde and prepared for frozen sections. Tissue sections were incubated with Hoechst 33342 for nuclei staining (blue) and mounted using Dako fluorescent mounting medium before analysis by an epifluorescence microscope. Representative images from each group are shown (original magnification x 10). 


\section{WN-Fc treatment enhances immune cell recruitment into tumors}

Increase lymphocyte infiltration within tumors has been observed in several tumors subsequent to therapy with Abs or with conventional therapies such as chemotherapy [26]. Since WN-Fc fusions inhibited tumor growth, we next assessed whether they would enhance immune cell infiltration into tumors. Immunohistochemical staining revealed an increase in $\mathrm{CD} 3+\mathrm{T}$ cells and $\mathrm{NK}$ cell infiltration in the tumors of WN-Fc-treated mice when compared to tumors-derived from mice treated with the Fc control (Figure 9, representative examples). WN-Fc-2 treatment seems to recruit more lymphocytes into tumors than that of WN-Fc-1. Regardless of the difference, the data support the use of WN-Fc fusion proteins to mobilize immune cells into tumor tissues.

\section{DISCUSSION}

Fc-based fusion proteins, in which the Fc domain of an antibody of the $\operatorname{IgG}$ isotype is fused to a different protein, have merged as an important class of new pharmaceuticals [27]. To date, most of the engineered Fc fusion proteins either work as antagonists to block receptor-ligand interactions or as agonists to stimulate the receptor function [27]. In this study, we have shown that $\mathrm{WN}-\mathrm{Fc}$ fusion proteins can serve as a potent activator for immune effector cells such as NK cells, monocytes, and DCs (Figure 10). Importantly, treatment of 4T1 tumorbearing mice with WN-Fc- fusion proteins inhibited tumor growth, providing support for the rational use of WN-Fc fusion proteins as adjuvant and tumor cell killers.

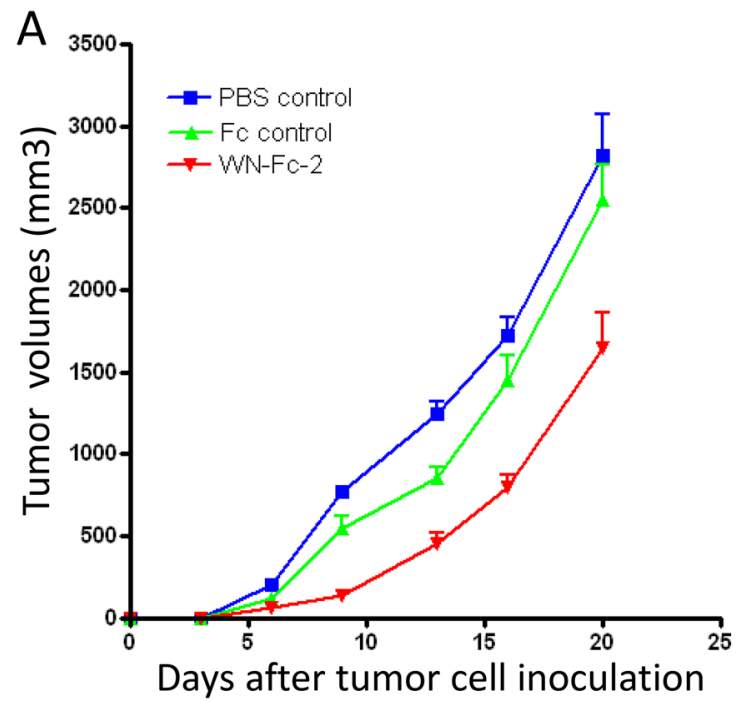

With respect to cancer immunotherapy, the Fc domain of $\mathrm{Ab}$ mediates cellular cytotoxic functions through its interactions with the Fc $\gamma$ receptors (activating receptors Fc $\gamma$ RI, Fc $\gamma$ RIIa and Fc $\gamma$ RIIIa; inhibitory receptor FcyRIIb). Moreover, cytokine production by innate immune cells seems to be important for clinical responses to therapeutic Abs [28]. Indeed, IFN- $\gamma$ and TNF- $\alpha$ are known to enhance NK cytotoxicity and macrophage phagocytosis of tumor cells [10]. Hence, the observation that both soluble and WN-Fc-coated tumor cells can activate innate immune cells is interesting. Given that soluble Fc control did not trigger cytokine production, it seems that the nature of the peptide sequence fused to the Fc domain clearly affects the effector function of the engineered proteins. Based on the present data, we thus propose that the structure formed by WN-Fc-1 and WN-Fc-2 fusion proteins may facilitate their interaction with the Fc $\gamma$ receptors expressed by innate immune cells. Even in the presence of $0.1 \%$ SDS and under reducing conditions, WN-Fc fusion proteins retained some conformational behavior (see Figure $1 \mathrm{~B}$ and $1 \mathrm{C}$ ). It should be noted that free WN peptide has no effect on innate immune cells, again arguing for WN-Fc structure-related effect. Moreover, none of the other tested soluble peptide Fc-fusions activated innate immune cells (data not shown), thus the observed adjuvant effect seems to be specific for WN-Fc fusion proteins.

As the immune response is a major determinant of therapeutic $\mathrm{Ab}$ efficacy in cancer patients, the opportunity now exists to combine $\mathrm{Ab}$ therapy with immunostimulators to enhance objective clinical responses [16]. Various strategies including stimulating the innate response and blocking inhibitory signals are being

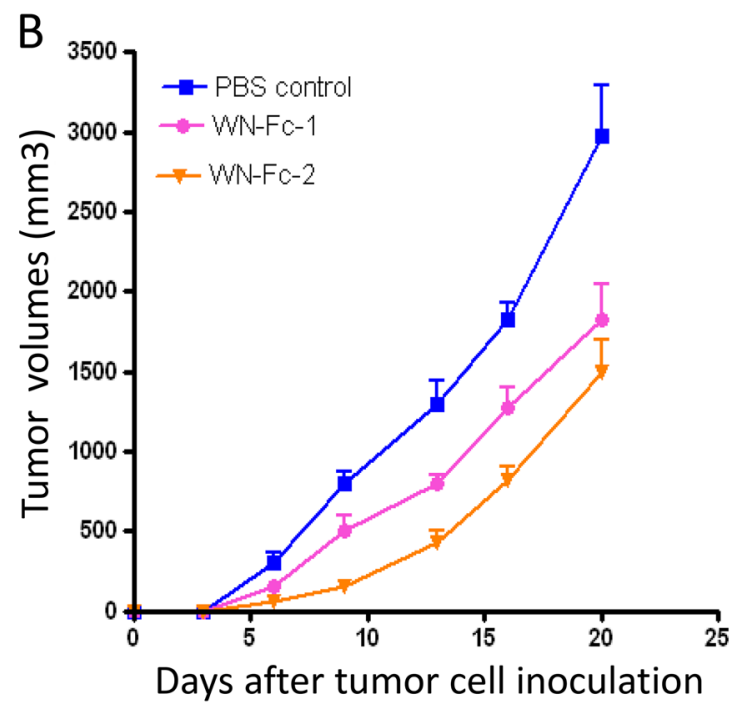

Figure 8: Inhibition of tumor growth in BALB/c mice. A. 4T1 s.c. tumor-bearing mice were treated on day 3 and 7 (i.v. injection) with PBS, Fc control or WN-Fc-2 (100 $\mu \mathrm{g} / 200 \mu$ l PBS per mouse). Tumor dimensions were measured and then volumes were calculated. Each point represents the mean of 7 determinations $(n=7)$ per group; bars $=$ SD. B. Effects of WN-Fc-1 and WN-Fc-2 on tumor growth. Experimental conditions are as in A. 


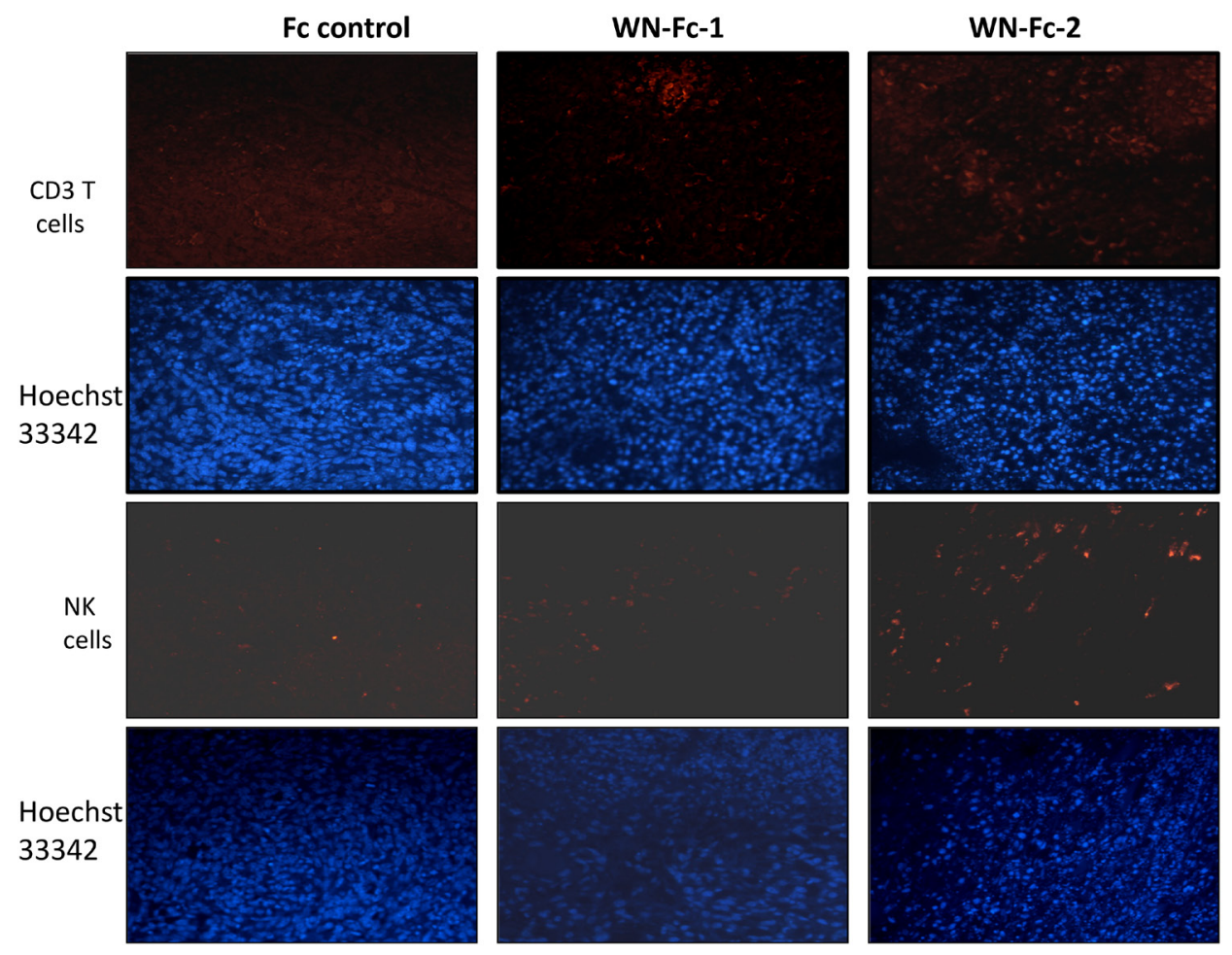

Figure 9: Analysis of T cells and NK cells infiltration into tumor tissues. Tumors were removed on day 14 after treatment and frozen sections were stained with phycoerytrin-conjugated mouse anti-CD3 or phycoerytrin-conjugated NKp46 monoclonal antibodies. Representative immunofluorescence microscopy images showing the presence of CD3 + T cells and NK cells in WN- Fc treated animals. Blue, Hoeschst 33342-stained nuclei.

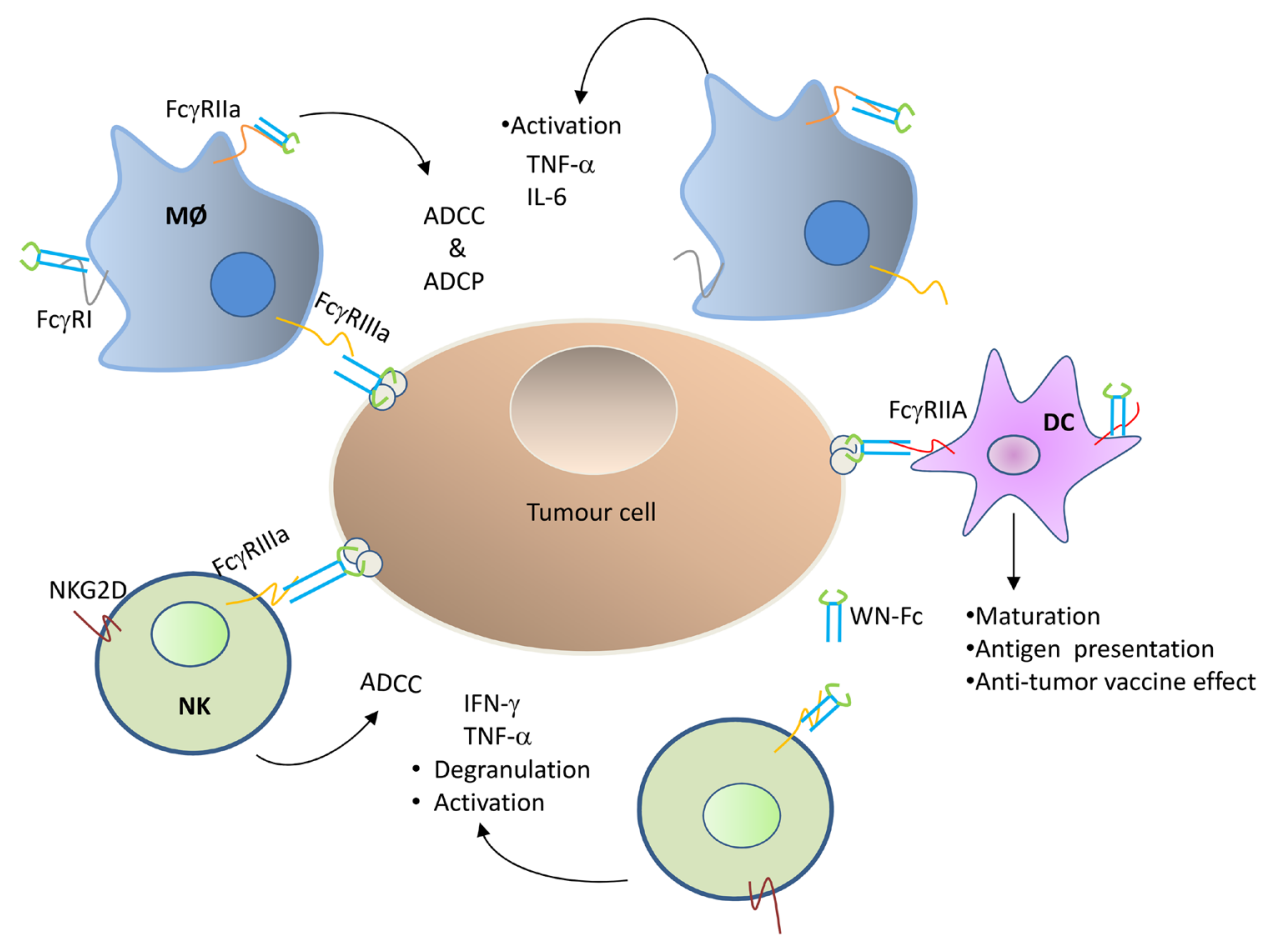

Figure 10: Schematic diagram showing Fcy receptor interaction with WN-Fc fusion proteins. Both soluble and NWFc-coated tumor cells activate innate immune cells such as NK cells, macrophages (MØ), and dendritic cells (DC) via different types of activating Fc- $\gamma$ receptors: Fc $\gamma$ R1 (CD64), Fc $\gamma$ RIIa (CD32a), Fc $\gamma$ RIIIa (CD16a). ADCC = antibody-dependent cellular cytotoxicity, ADCP $=$ antibody-dependent cellular phagocytose. 
explored in combination with Abs [17, 18]. With respect to cytokines, IL-15 has many activating and homeostatic functions on lymphocytes, and functions at different stages of the immune response by expanding and activating NK cells [29]. Ajuvants such as $\mathrm{CpG}$ oligodeoxynucleotides (ODN) and RNA oligonucleotides, ligands for Toll like receptors (TLRs) 9 and 7/8, respectively, have been used in cancer immunotherapy [30, 32]. In this respect, Moga and colleagues showed that IL-15 or CpG ODN can enhance rituximab-induced ADCC against B-cell lymphoma [32]. TLR ligands also activated NK cells and enhanced trastuzumab- and rituximab-induced ADCC invitro and in-vivo [33-35]. Similarly, immunomodulatory drugs such as lenalidomide enhanced rituximab-induced ADCC against lymphoma cell lines and primary B-cell chronic lymphocytic leukemia cells via NK cells and monocyte activation [36]. Together, these observations are consistent with the notion that immune-enhancing properties of various agents can improve $\mathrm{Ab}$ therapeutic efficacy.

In principle, an ideal cancer therapeutic protein should not only engage Fc $\gamma$ RIIIA on NK cells, but also activate other innate cells, particularly macrophages and DCs. By undergoing activation and maturation, DCs are expected to present tumor antigens/neoantigens to $\mathrm{T}$ cells. To prevent an excessive and prolonged response that could result in tissue destruction or autoimmunity, activated immune cells are controlled via the expression of co-inhibitory molecules [2, 37]. Activated T cells, macrophages, and NK cells express multiple co-inhibitory receptors and intracellular factors. While these immune checkpoint factors control the normal function of the immune system, when expressed during immunotherapy, they represent a significant barrier for the induction of a strong and sustained anti-tumor immune response, which is required for tumor cell destruction. In addition to the adjuvant effect, signaling via TLR or IL15 receptor also induces the expression of suppressor of cytokine signalling (SOCS) proteins, particularly SOCS-1, that attenuate or terminate intracellular signalling [38, 39]. Therefore, blocking of SOCS-1 expression in adoptive transferred NK cells or $\mathrm{T}$ cells could further enhance anti-tumour potency of this form of therapy [40].

Immune-compromised models such as human cell line derived xenografts are useful for assessing the preclinical responses to conventional cancer treatments. However, the use of immune-competent models is essential when studying the effects of immunotherapeutics. The designed WN-Fc fusions proved to be effective in inhibiting 4T1 tumor growth in immune-competent $\mathrm{BALB} / \mathrm{c}$ mice. The selected therapeutic dose (around 5 $\mathrm{mg} / \mathrm{kg}$ ) is based on preclinical studies with Abs [23, 27]. Under our experimental conditions, no side effects such as loss of weight and decrease in spontaneous movement were seen in mice exposed to 5,10 , and or $15 \mathrm{mg} / \mathrm{kg}$ dose. Notably, WN-Fc treatment enhanced CD3 T cells and NK cells infiltration into tumor tissues. Subsequent to activation, NK cells mediate their effector functions through perforin and granzyme release as well as secretion of cytokines such as IFN- $\gamma$ and TNF- $\alpha$ [10]. Similarly, treatment with either CTLA-4 or PD1 blocking antibodies increased lymphocyte infiltration in tumor tissues [41, 42].

Although the identified WN peptide can be used to direct innate immune cells against tumor cells without knowledge of its cellular receptor, moving this peptide towards clinical use will be facilitated by the identification of its binding receptor. We have performed a series of experiments (e.g. affinity capture, immunoprecipitation) to identify the WN-peptide receptor and the data suggest the involvement of several glycoproteins. Hence, the binding may arise from the formation of a native conformational epitope involving the interaction of more than one protein. Such interaction is more likely to be lost upon the preparation of membrane proteins. While further work is needed before patients with cancer can be treated with the WN-Fc fusion proteins, the results identify an unexpected effect of soluble WN-Fc fusions on innate immune cells and support efforts to evaluate the potential of the engineered peptide- Fc fusion proteins for use in cancer immunotherapy.

\section{MATERIALS AND METHODS}

\section{Cells and antibodies}

Human cancer cell lines SKBR3 (breast), SW900 (lung), T98G (glioma), and murine 4T1 breast carcinoma cell line were obtained from the American Type Culture Collection (ATCC, Rockville, MA). Human peripheral blood mononuclear cells (PBMCs) were isolated from buffy coats by lymphoprep density gradient centrifugation. Monocytes were enriched from PBMCs using plastic adherence and purification was verified by phenotypic analysis of the surface marker CD14+. To generate M1 and M2 macrophages, monocytes were cultured for 6 days in RPMI-1640 medium in the presence of $100 \mathrm{ng} / \mathrm{ml} \mathrm{GM-CSF}$ (M1) or $100 \mathrm{ng} / \mathrm{ml}$ M-CSF (M2) as described by Rey-Giraud et al. [43]. NK cells were purified from PBMCs using NK cell isolation kit and auto MAC Pro Separator according to the manufacturer's instructions (Miltenyi Biotec, $\mathrm{GmbH}$ ). Purification was verified by phenotypic analysis of the surface marker CD56. Cells were cultured in RPMI-1640 or DMEM supplemented with $10 \%$ heat-inactivated fetal calf serum and antibiotics. Cell stimulation with WN-Fc-1 or WN-Fc-2 was performed in X-VIVO 15 medium (Lonza, Basel, Switzerland). Approval for obtaining buffy coats from normal volunteers was granted by Oslo University Hospital Ethics Committee. Anti-CD56 and Anti-CD107a antibodies were purchased from BD Pharmingen (San Diego, CA, USA). FITC-conjugated anti-human Fc 
was purchased from Sigma (St. Louis MO USA). PEconjugated anti-CD14, anti-CD80, anti-CD86, and antiCD69 monoclonal antibodies were purchased from Dako (Glostrup, Denmark). PE-conjugated mouse anti-CD3 and anti-NKp46 were purchased from Biolegend.

\section{Cytokine production and NK cell degranulation}

PBMCs, monocytes, M1 and M2 macrophages, immature DCs and NK cells were cultured for 16 $\mathrm{h}$ in X-VIVO 15 medium supplemented with WNFc-1, WN-Fc-2, or Fc control (5 or $10 \mu \mathrm{g} / \mathrm{ml}$ each). Subsequently, culture supernatants were collected and cytokine contents were measured by ELISA. CD69 expression as marker for NK activation was analyzed by FACS subsequent to $16 \mathrm{~h}$ stimulation time. To measure surface expression of CD107a/LAMP-1, a surrogate marker for NK cell degranulation, NK cells ( $5 \times 10^{4}$ in $200 \mu \mathrm{l}$ X-VIVO medium) were stimulated with WN-Fc-1, WN-Fc-2, or Fc control $(10 \mu \mathrm{g} / \mathrm{ml})$. During stimulation, PE-Cy5 conjugated anti-CD107a (2 $\mu \mathrm{l} /$ well $)$ and monensin $(0.2 \mu \mathrm{l} /$ well $)$ were added to the cells. After $5 \mathrm{~h}$ incubation at $37^{\circ} \mathrm{C}$, the cells were harvested, washed, stained with FITC conjugated anti-CD56 and then analyzed by FACSCanto II flow cytometer (BD Biosciences, San Jose, CA, USA). All flow data were analyzed by flowJo software.

\section{Oligonucleotides, cloning, and expression}

The following overlapping DNA oligonucleotides encoding peptides were made and HPLC purified by Eurofins Genomics (Ebersberg, Germany).

WN-Fc-1 peptide (WNLPWYYSVSPT) 5' -aattcgtgg aatcttccttggtattatagcgtcagtcctacgggtggaggca-3' 5'-gatctgcct ccaccegtaggactgacgctataataccaaggaagattccacg-3' WN-Fc-2 peptide (WNLPWYYSVSPTGGGWNLPWYYSVSPT) 5 '-aattcgtggaatcttccttggtattatagcgtcagtcctacgggtggaggctggaa tcttccttggtattatagcgtcagtcctacgggtggaggca-3' 5'-gatctgcctc cacccgtaggactgacgctataataccaaggaagattccagcctccacccgtagga ctgacgetataataccaaggaagattccacg-3' Fc control peptide (ISAMVRS) 5' -aattcgatatcggccatggtta-3' 5' -aattcgatatcggcc atggtta-3'

DNA oligonucleotides were annealed together to form a double stranded sequence with overhanging bases for EcoR1 and BglII restriction sites and then cloned into EcoR1-BglII-cleaved pFuse-hIgG1-Fc2 vector in frame with IL-2 signal sequence and the Fc portion of human IgG1 (In vivoGen, San Diego, CA, USA). Recombinant peptide Fc fusion proteins were produced by transient transfection of the plasmids into HEK293T cells and purified by protein $\mathrm{G}$ chromatography. Protein purity was determined by electrophoresis on $10 \%$ sodium dodecyl sulfate (SDS) polyacrylamide gel and positive fractions were collected, $\mathrm{pH}$ adjusted to 7.5 and then stored at $-80^{\circ} \mathrm{C}$ until use.

\section{Flow cytometry}

The binding of the WN-Fc fusion proteins to cancer cells was analyzed by flow cytometry. In brief, aliquots of cells $\left(10^{5}\right)$ were divided into conical 96-well micro-plate, washed with PBS buffer containing $1 \%$ FCS, and then incubated with the affinity-purified peptide-Fc fusions for 30 min on ice. After washing, cells were incubated with FITC-conjugated anti-human Fc for $30 \mathrm{~min}$ on ice and then analyzed by flow cytometry.

\section{Antibody dependent cellular cytotoxicity assay (ADCC)}

ADCC was conducted using the lactate dehydrogenase (LDH) cytotoxicity kit in accordance with manufacturer's instructions (Promega, Madison, WI, USA). Cancer cells pre-treated with the peptide-Fc fusions $(10 \mu \mathrm{g} / \mathrm{ml})$ were incubated with IL-15-activated NK cells for $18 \mathrm{~h}$ at $37^{\circ} \mathrm{C}$. NK cells were prepared from human peripheral blood mononuclear cells. After incubation, culture supernatants were transferred to a 96-well plate to determine the amount of $\mathrm{LDH}$ released. Percentage of cell lysis in the cytotoxicity assays was calculated as (experimental release - background release/maximum release - background release) x 100. The effector-totarget ratio 12:1 and 25:1 was determined from pilot experiments.

\section{Analysis of NW-Fc fusion protein binding to 4T1 cells by fluorescence microscopy}

4T1 cells were cultured in Lab-Tek chamber slides (Nalge Nunc International, Naperville, USA) for $24 \mathrm{~h}$ in X-VIVO 15 medium. Then the medium was replaced with fresh medium and the cells were incubated with Rhodamine conjugated WN-Fc fusion proteins $(10 \mu \mathrm{g} / \mathrm{ml})$ for $30 \mathrm{~min}$ at $4^{\circ} \mathrm{C}$. Subsequently, the cells were washed and incubated at $37^{\circ} \mathrm{C}$ for $2 \mathrm{~h}$ to allow internalization, followed by $5 \mathrm{~min}$ incubation with Hoechst 33342. The cells were washed twice with PBS and fixed with 4\% paraformaldehyde for $15 \mathrm{~min}$ at $4^{\circ} \mathrm{C}$. After washing, slides were covered with Dako cytomation fluorescent mounting medium and then images were taken with a confocal microscope (Zeiss LSM 510, Olympus, Tokyo, Japan).

\section{Treatment of subcutaneous 4T1 metastatic breast cancer}

Female BALB/c mice were purchased from Harlan (Boxmeer, The Netherlands) and housed according to the experimental animal guidelines. They were acclimated to the new environment for at least one week after arrival before being used in experiments. The murine 4T1 breast carcinoma cell line was grown in monolayer culture and harvested by trypsinization prior to cell inoculation. 
BALB/c female mice 5 to 7 weeks of age were injected subcutaneously with $25 \times 10^{5}$ tumor cells and mice were randomized into three different treatment groups ( 7 mice per group). Test molecules were administrated intravenously at day 2 and 7 after tumor inoculation (100 $\mu \mathrm{g} /$ mouse/injection). Animals were assessed daily for clinical symptoms and adverse effects. Tumor growth was monitored until sacrifice at day 20. The same experimental conditions were used for the next set of experiments. All experiments involving mice were approved by the National Animal Research Authority (Oslo, Norway) and performed according to international standards.

\section{Analysis of the tumor-associated WN-Fc fusion proteins by fluorescence microscopy}

Around two weeks after tumor cell inoculation, rhodamine conjugated $\mathrm{WN}-\mathrm{Fc}$ fusion proteins were injected intravenously into separate animals using $200 \mu \mathrm{g}$ of the conjugate in $100 \mu \mathrm{l}$ of physiological saline. Mice were sacrificed $18 \mathrm{~h}$ after injection and tumors and other organs (lungs, kidneys and heart) were removed and incubated overnight in 4\% paraformaldehyde solution and then embedded in optimal cutting temperature medium (OCT). Tissue sections were incubated with Hoechst 33342 for nuclei staining. Thereafter, the slides were covered with Dako cytomation fluorescent mounting medium before examination under an epifluorescence microscope (Leica DM RHC, Leica Microscopy As, Oslo).

\section{Analysis of tumour infiltrating lymphocytes}

Detection of $\mathrm{T}$ cells and NK cells in tumors and normal organ tissues was conducted according to standard immunohistochemical methods using 5- $\mu \mathrm{m}$ sections of OCT-embedded tumors or organ tissues fixed with paraformaldehyde. For detection of T cells and NK cells, a rat anti-mouse CD3 conjugated to $\mathrm{PE}$ and a rat antiNKp46 conjugated to PE were used, respectively. Before incubation with antibodies, sections were blocked with $5 \%$ rat serum in PBS.

\section{Statistical analysis}

Results are reported as means \pm SD. Statistical significance of differences was assessed by student's $t$ test. Anti-tumor activity of the test molecules was assessed by a two-tailed test. The level of significance was set at a $\mathrm{P}$ value of less than 0.05 .

\section{ACKNOWLEDGMENTS}

This work was supported by the Norwegian Cancer society and OUH-Gene Therapy Program to MS. We thank Dr. Morten Oksvold for helping with the confocal microscope.

\section{CONFLICTS OF INTEREST}

The authors declare no competing financial interest.

\section{REFERENCES}

1. Guan X. Cancer metastases: challenges and opportunities. Acta Pharm Sin B. 2015; 5: 402-418.

2. Sharma P, Allison JP. Immune checkpoint targeting in cancer therapy. Cell. 2015; 161: 205-214.

3. Snyder A, Makarov V, Merghoub T, Yuan J, Zaretsky JM, Desrichard A, Walsh LA, Postow MA, Wong P, Ho TS, Hollmann TJ, Bruggeman C, Kannan K, et al. Genetic basis for clinical response to CTLA-4 blockade in melanoma. N. Engl. J. Med. 2014; 371: 2189-2199.

4. Rizvi NA, Hellmann MD, Snyder A, Kvistborg P, Makarov V, Havel JJ, Lee W, Yuan J, Wong P, Ho TS, Miller ML, Rekhtman N, Moreira AL, et al. Cancer immunology. Mutational landscape determines sensitivity to PD-1 blockade in non-small cell lung cancer. Science. 2015; 348:124-128.

5. Tsirigotis P, Savani BN, Nagler A. Programmed death-1 immune checkpoint blockade in the treatment of hematological malignancies Ann Med. 2016; 25: 1-12.

6. Leone P, Shin EC, Perosa F, Vacca A, Dammacco F, Racanelli V. MHC class I antigen processing and presenting machinery: organization, function, and defects in tumor cells. J. Natl. Cancer Inst. 2013; 105: 1172-1187.

7. Redman JM, Hill EM, AlDeghaither D, Weiner LM. Mechanisms of action of therapeutic antibodies for cancer. Mol. Immunol. 2015; 67: 28-45.

8. Weiner LM, Surana R, Wang S. Monoclonal antibodies: versatile platforms for cancer immunotherapy. Nat. Rev. Immunol. 2010; 10: 317-327.

9. Seidel UJ, Schlegel P, Lang P. Natural killer cell mediated antibody-dependent cellular cytotoxicity in tumor immunotherapy with therapeutic antibodies. Front. Immunol. 2013; 4: 76.

10. Vivier E, Tomasello E, Baratin M, Walzer T, Ugolini S. Functions of natural killer cells. Nat. Immunol. 2008; 5: 503-510.

11. Beck A, Wurch T, Bailly C, Corvaia N. Strategies and challenges for the next generation of therapeutic antibodies. Nat. Rev. Immunol. 2010; 10: 345-352.

12. Brandsma AM, Jacobino SR, Meyer S, ten Broeke T, Leusen JH. Fc receptor inside-out signaling and possible impact on antibody therapy. Immunol. Rev. 2015; 268: 74-87.

13. Long EO, Kim HS, Liu D, Peterson ME, Rajagopalan S. Controlling natural killer cell responses: integration of signals for activation and inhibition. Annu. Rev. Immunol. 2013; 31: 227-258. 
14. Lee CM, Tannock IF. The distribution of the therapeutic monoclonal antibodies cetuximab and trastuzumab within solid tumors. BMC Cancer. 2010; 10: 255.

15. Sioud M, Westby P, Olsen JK, Mobergslien A. Generation of new peptide-Fc fusion proteins that mediate antibodydependent cellular cytotoxicity against different types of cancer cells. Mol. Ther. Methods Clin. Dev. 2015; 2: 15043.

16. Kohrt HE, Houot R, Marabelle A, Cho HJ, Osman K, Goldstein M, Levy R, Brody J. Combination strategies to enhance antitumor ADCC. Immunotherapy. 2012; 4: 511-527.

17. Houot R, Kohrt H, Goldstein MJ, Levy R. Immunomodulating antibodies and drugs for the treatment of haematological malignancies. Cancer Metastasis Rev. 2011; 30: 97-109.

18. Giron-Michel J, Giuliani M, Fogli M, Brouty-Boyé D, Ferrini S, Baychelier F, Eid P, Lebousse-Kerdilès C, Durali D, Biassoni R, Charpentier B, Vasquez A, Chouaib S, et al. Membrane-bound and soluble IL-15/IL-15Ralpha complexes display differential signaling and functions on human hematopoietic progenitors. Blood. 2005; 106: 2302-2310.

19. Alter G, Malenfant JM, Altfeld M. CD107a as a functional marker for the identification of natural killer cell activity. J. Immunol. Methods. 2004; 294: 15-22.

20. Cohnen A, Chiang SC, Stojanovic A, Schmidt H, Claus M, Saftig P, Janßen O, Cerwenka A, Bryceson YT, Watzl C. Surface CD107a/LAMP-1 protects natural killer cells from degranulation-associated damage. Blood. 2010; 122: 1411-1418.

21. Konjevic G, Jurisic V, Jovic V, Vuletic A, Mirjacic Martinovic K, Radenkovic S, Spuzic I. Investigation of NK cell function and their modulation in different malignancies. Immunol. Res. 2012; 52: 139-156.

22. Shadidi M, Sioud M. Identification of novel carrier peptides for the specific delivery of therapeutics into cancer cells. FASEB J. 2003; 17: 256-258.

23. Gerdes CA, Nicolini VG, Herter S, van Puijenbroek E, Lang S, Roemmele M, Moessner E, Freytag O, Friess T, Ries CH, Bossenmaier B, Mueller HJ, Umaña P. GA201 (RG7160): a novel, humanized, glycoengineered antiEGFR antibody with enhanced ADCC and superior in vivo efficacy compared with cetuximab. Clin. Cancer Res. 2013; 19: 1126-1138.

24. Overdijk MB, Verploegen S, Ortiz Buijsse A, Vink T, Leusen JH, Bleeker WK, Parren PW. Crosstalk between human IgG isotypes and murine effector cells. J. Immunol. 2012; 189: 3430-3438.

25. Winiarska M, Bojarczuk K, Pyrzynska B, Bil J, Siernicka M, Dwojak M, Bobrowicz M, Miazek N, Zapala P, Zagozdzon A, Krol M, Syta A, Podszywalow-Bartnicka P. et al., Inhibitors of SRC kinases impair antitumor activity of anti-CD20 monoclonal antibodies. MAbs. 2014; 6: 1300-1313.
26. Finn OJ. Immuno-oncology: understanding the function and dysfunction of the immune system in cancer. Ann Oncol. 2012; Suppl 8:viii6-9.

27. Hang C. Receptor- Fc fusion therapeutics, traps, and mimetibody technology, Curr. Opin Biotechnol. 2009; 20: 692-699.

28. O'Sullivan T, Saddawi-Konefka R, Vermi W, Koebel CM, Arthur C, White JM, Uppaluri R, Andrews DM, Ngiow SF, Teng MW, Smyth MJ, Schreiber RD, Bui JD. Cancer immunoediting by the innate immune system in the absence of adaptive immunity. J. Exp. Med. 2012; 209: 1869-1882.

29. Fehniger TA, Caligiuri MA. Interleukin 15 : biology and relevance to human disease. Blood. 2001; 97: 14-32.

30. Verthelyi D, Klinman DM. Immunoregulatory activity of CpG oligonucleotides in human and nonhuman primates. Clin. Immunol. 2003; 109: 64-71.

31. Sioud M. Innate sensing of self and non-self RNAs by Tolllike receptors. Trends. Mol. Med. 2006; 4:167-76.

32. Moga E, Alvarez E, Cantó E, Vidal S, Rodríguez-Sánchez JL, Sierra J, Briones J. NK cells stimulated with IL-15 or $\mathrm{CpG}$ ODN enhance rituximab-dependent cellular cytotoxicity against B-cell lymphoma. Exp. Hematol. 2008; 36: 69-77.

33. Wang H, Rayburn ER, Wang W, Kandimalla ER, Agrawal $\mathrm{S}$, Zhang R. Immunomodulatory oligonucleotides as novel therapy for breast cancer: pharmacokinetics, in vitro and in vivo anticancer activity, and potentiation of antibody therapy. Mol. Cancer Ther. 2006; 8: 2106-2114.

34. Lu H, Yang Y, Gad E, Inatsuka C, Wenner CA, Disis ML, Standish LJ. TLR2 agonist PSK activates human NK cells and enhances the antitumor effect of HER2-targeted monoclonal antibody therapy. Clin. Cancer Res. 2011; 17: 6742-6753.

35. Rosa R, Melisi D, Damiano V, Bianco R, Garofalo S, Gelardi T, Agrawal S, Di Nicolantonio F, Scarpa A, Bardelli A, Tortora G. Toll-like receptor 9 agonist IMO cooperates with cetuximab in K-ras mutant colorectal and pancreatic cancers. Clin. Cancer Res. 2011; 17: 6531-6541.

36. Wu L, Adams M, Carter T, Chen R, Muller G, Stirling D, Schafer P, Bartlett JB. Lenalidomide enhances natural Killer cell and monocyte-mediated antibody-dependent cellular cytotoxicity of rituximab-treated CD20+ tumor cells. Clin. Cancer Res. 2008; 14: 4650-4657.

37. Sioud M. New insights into mesenchymal stromal cellmediated T-cell suppression through galectins. Scand J Immunol. 2011; 73:79-84.

38. Ramsborg CG, Papoutsakis ET. Global transcriptionoal analysis delineates the differential inflammatory response interleukin-15 elicits from cultured human T cells. Exp. Hem. 2007; 35: 454-464.

39. Kubo M, Handa T, Yoshimura A. Suppressors of cytokine signaling and immunity. Nat. Immunol. 2003; 4: 1169-1176. 
40. Sioud M. Engineering better immunotherapies via RNA interference. Hum. Vaccin. Immunother. 2014; 11: 3165-3174.

41. Soares KC, Rucki AA, Wu AA, Olino K, Xiao Q, Chai Y, Wamwea A, Bigelow E, Lutz E, Liu L, Yao S, Anders RA, Laheru D, et al. PD-1/PD-L1 blockade together with vaccine therapy facilitates effector T-cell infiltration into pancreatic tumors. J. Immunother. 2015; 38: $1-11$.
42. Das R, Verma R, Sznol M, Boddupalli CS, Gettinger SN, Kluger H, Callahan M, Wolchok JD, Halaban R, Dhodapkar MV, Dhodapkar KM. Combination therapy with antiCTLA-4 and anti-PD-1 leads to distinct immunologic changes in vivo. J. Immunol. 2015; 194: 950-959.

43. Rey-Giraud F, Hafner M, Ries CH. In vitro generation of monocyte-derived macrophages under serum-free conditions improves their tumour promoting functions, PloS One. 2012; 7: e42656. 